\title{
Does Free Will Require Alternative Possibilities?
}

\author{
Pablo Rychter \\ University of Valencia \\ BIBLID [0873-626X (2017) 45; pp. 131-146] \\ DOI: $10.1515 /$ disp-2017-0001
}

\begin{abstract}
In this introductory study I discuss the notion of alternative possibilities and its relation to contemporary debates on free will and moral responsibility. I focus on two issues: whether Frankfurt-style cases refute the principle of alternative possibilities, and whether alternative possibilities are relevant to grounding free will and moral responsibility. With respect to the first issue, I consider three objections to Frankfurt-syle cases: the flicker strategy, the dilemma defense, and the objection from new dispositionalism. With respect to the second issue, I consider the debate between Alternative Possibilities views and Actual Sequence views, as framed by Carolina Sartorio in her Causation and Free Will. I then explain how these two issues are relevant to the papers included in this volume.
\end{abstract}

\section{Keywords}

Alternative possibilities, Frankfurt, actual sequence, free will, moral responsibility.

\section{Alternative possibilities and Frankfurt-style cases}

Much of the recent, and not so recent, debate on free will and moral responsibility has focused on the notion of alternative possibilities: on whether an agent could have done otherwise than she actually did. A central question in this area is whether alternative possibilities are a necessary condition for free will. This was in fact the question that motivated the II Blasco Disputatio, at which the papers collected here were originally presented. In this introductory study, I intend to clarify the notion of alternative possibilities and its relation to contemporary debates on free will and moral responsibility. I will focus 
on two issues: whether Frankfurt-style cases refute the principle of alternative possibilities, and whether alternative possibilities are relevant to grounding free will and moral responsibility.

Let us start by identifying the notions of free will and moral responsibility that are relevant to our central question ('does free will require alternative possibilities') and to the discussions in this volume. The notion of moral responsibility that we are interested in may be pinned down by its relations with the notion of desert. We say that an agent, $\mathrm{S}$, is morally responsible for $\mathrm{A}$ (and the consequences of A) when it would be appropriate to blame or praise S for A (here we can take A to be any 'ordinary action' involving bodily movements, like shooting a gun, but also 'mental actions' like deciding or choosing to shoot a gun, and even omissions like not shooting a gun). That is to say, an agent deserves blame or praise only for that which she is morally responsible for. What does it take for an agent to be morally responsible in this sense? There are probably many relevant conditions that should be mentioned even in a schematic answer to this question. However, for our present purposes, we can focus on just one: it seems that $\mathrm{S}$ is morally responsible for $\mathrm{A}$ only if $\mathrm{S}$ enjoys some kind of freedom in performing A; only if performing A is the result of S's free will. Thus, it seems initially plausible that enjoying some kind of free will is a metaphysical condition on moral responsibility, although those who think that we have no free will at all will either disagree with this, or claim that, likewise, we are never morally responsible. What does it take for an agent to enjoy free will? Again, there are probably many relevant conditions that should be mentioned even in a schematic answer to this question. For our present purposes, though, we can focus only on those conditions that have to be met in order to account for moral responsibility. That is to say, even if there could be much more to be said about what freedom is (and about whether it obtains or not), we need only focus on what is sometimes called the free-will condition on moral responsibility or, alternatively, the free will that is relevant to moral responsibility. It is this restricted notion of free will that we have in mind when we ask our central question of whether alternative possibilities are necessary for free will, and it is the notion I will focus on in what follows.

Having identified the relevant notion of free will, let us turn now to the notion of alternative possibilities. It seems initially plausible 
that, in order for $\mathrm{S}$ to perform A freely, it must be possible for $\mathrm{S}$ to do otherwise than A. That is, it must be possible for $\mathrm{S}$ not to perform A. If $S$ could not avoid doing $A$ at all, $S$ is not really free with respect to A. This is the notion of alternative possibilities we are interested in, and the plausible-sounding claim we are considering is the basis of what Harry Frankfurt (1969) called the Principle of Alternative Possibilities (PAP): 'a person is morally responsible for what he has done only if he could have done otherwise'. Unlike this formulation of PAP, we are focusing on the free-will condition on moral responsibility, rather than on moral responsibility itself, and our central question is 'are alternative possibilities a necessary condition on free will, as it intuitively seems to be the case?' Frankfurt famously argued that they are not. His argument was based on what is commonly referred to as a 'Frankfurt-style scenario' (FSC), which is a case with the following basic features: an agent, Jones, performs A as a result of his own reasoning and decision. ${ }^{1}$ However, unbeknownst to Jones, there is a second agent, Black, who monitors Jones' process of deliberation leading to A. Black is interested in Jones' performing A and so, if Black thought, as result of his monitoring of Jones' process of deliberation, that Jones was not going to perform A, he would have intervened (using perhaps advanced neuro-scientific technology) to cause Jones to perform A. However, Black prefers not to intervene if it is not necessary and, as it happens, it is not. Jones performs A through his own decision. ${ }^{2}$ About such a case, most people have

\footnotetext{
${ }^{1}$ Here, again, we can take 'A' to range over overt actions, mental actions, and omissions. Frankfurt's original example seems to involve an ordinary action, but later FSCs are built around mental actions, so that in these examples Black has control over Jones' decisions and choices. Even if for ease of exposition I will sometimes focus on cases of the first sort, I take my discussion to apply equally to both.

${ }^{2}$ Frankfurt's original description of the case is as follows: 'Suppose someone - Black, let us say — wants Jones to perform a certain action. Black is prepared to go to considerable lengths to get his way, but he prefers to avoid showing his hand unnecessarily. So he waits until Jones is about to make up his mind about what to do, and he does nothing unless it is clear to him (Black is an excellent judge of such things) that Jones is going to decide to do something other than what he wants him to do. If it does become clear that Jones is going to decide to do something else, Black takes effective steps to ensure that Jones decides to do, and that he does do, what he wants him to do'. (Frankfurt 1969: 835)
} 
the following two intuitions: (i) Jones is morally responsible with respect to A, and (ii) Jones could not have done otherwise. These two intuitions, if taken at face value, would be enough to refute PAP and to give a negative answer to our question of whether free will requires alternative possibilities.

FSCs have been object of an intense and on-going debate that is about to reach its fiftieth anniversary. In order to fully appreciate the implications of FSCs for our understanding of free will and moral responsibility, it is, in my opinion, useful to distinguish two questions: (i) do FSCs succeed as counterexamples to PAP? (ii) do FSCs succeed in motivating an account of free will and moral responsibility in which alternative possibilities play no explanatory role? These are, in my opinion, two independent and open questions, and I will briefly consider each of them in the next two sections. My purpose is not to offer a comprehensive discussion of the questions, but rather to offer some hints that may be useful to the reader of the papers included in this issue.

\section{Do Frankfurt-style cases succeed in refuting PAP?}

In order to address the question whether FSCs are successful counterexamples to PAP, it will be useful to consider the debate between compatibilists and incompatibilists, i.e. between those who affirm and those who deny that free will is compatible with the truth of causal determinism, which for our present purposes we can define as the view that the laws of nature, together with the present state of the world, completely determine how things will be in the future. This is so because PAP plays a prominent role in what may be called the master argument for incompatibilism: (P1) An agent $\mathrm{S}$ is free with respect to A only if S could have avoided doing A; (P2) If causal determinism is true, nobody can avoid doing what they actually do (as it sometimes said, what they actually do is a necessary consequence of the past and the laws of nature). Therefore, (C) If determinism is true, nobody is free with respect to anything. The fact that PAP is a premise of this argument has two important consequences for our present discussion. On the one hand, it is clear that if FSCs succeed, a major argument for incompatibilism is compromised. On the other, in order for FSCs to be dialectically appropriate against incompatibilism, they 
must not rest too directly on views that an incompatibilist would obviously reject.

With this background in mind we can now ask: do FSCs actually refute PAP? In order to do so, our intuitive judgments about Jones (that he is morally responsible for what he did, and that he could not have done otherwise) should be true. But it has been argued on different grounds that they are not, and that, contrary to appearances, Jones could have done otherwise. Let us briefly consider three arguments for this conclusion.

\subsection{The flicker strategy}

According to a first argument, even if Jones could not avoid doing A, he could at least try or intend not to do A. In fact, one might think that some such possibility is constitutive of FSCs: it is because of Black's sensitivity to such a possibility that he is able to tell whether or not his intervention is necessary. In other words, it seems to be part of a FSC that Jones could have behaved, in some respect, significantly differently from how he actually did: he could have behaved in a way (perhaps by trying or intending not to do A) such that Black would have judged that his intervention was needed. This becomes clearer in those FSCs that, unlike Frankfurt's original example, involve some prior sign of Jones' subsequent behaviour. The prior sign is an event in Jones' deliberation process, which Black uses in order to determine whether his intervention is needed or not. Its presence is a reliable indicator that Jones will do A, and its absence by a suitable time would have triggered Black's intervention. In this kind of FSCs, it is clear that, in a way, Jones could have done otherwise than he actually did: he could have failed to give the prior sign and triggered Black's intervention. But then there was, after all, an alternative possibility open to him, and thus we do not have a counterexample to PAP. For reasons that will be clear shortly, this argument is known as the flicker strategy.

There are, in my view, two complementary answers to this argument. A first, straightforward answer goes like this: that Jones could have tried to do otherwise (or fail to give the appropriate prior sign) is of course a counterfactual possibility, but it is not an alternative possibility in the sense that is relevant to a defence of PAP. It is not a 
scenario in which Jones does otherwise in the sense of doing other than $A$. He only does otherwise in the sense of doing A by different means; means that involve the intervention of Black. This is too weak a sense of 'doing otherwise'. What PAP arguably requires is that an agent be able to do other than $A$, rather than just merely to do A by different means. In my opinion, this straightforward reply is enough to resist the present argument against the efficacy of FSCs. However, it can be combined with the kind of reply developed by Fischer (1994) and others since then. Fischer focuses on cases where Black's intervention is triggered by the 'presence of some involuntary sign, such as a blush or twitch or even a complex neurophysiological pattern', and notes that, even if it is true that Jones could have shown this sign, so showing that it is an alternative possibility, such alternative possibility is a mere 'flicker of freedom'. Flickers of freedom like that are not under the agent's control and they are therefore not robust enough as to ground attributions of moral responsibility (it would be implausible to say that Jones is morally responsible for what he did partly because he did not blush or show the relevant neurological pattern). It may be suggested that PAP should be understood as requiring the existence of robust alternative possibilities, and so the mere flickers of freedom that FSCs allow for are not enough to save PAP from refutation. Part of the literature on FSCs deals with the issue of what it takes for an alternative possibility to be robust in the required sense. In my opinion, most of that discussion is relevant for the question of what grounds free will (to be addressed in the next section) and can be bypassed here. For the present purposes we can say, following the suggestion of our first straightforward answer to the argument, that a counterfactual possibility is a robust alternative to doing A (and thus relevant to the truth of PAP, if the principle is understood as suggested above) if it is a possibility of failing to do $A$.

\subsection{The dilemma defence}

A second argument against the efficacy of FSCs as counterexamples to PAP is what is sometimes called the dilemma defence, versions of which were presented by Kane (1996), Widerker (1995), and Ginet (1996). The argument is based on the idea that FSCs must involve a prior sign that Jones will do A, and starts with the following dis- 
junction: either the occurrence of the prior sign causally determines Jones' subsequent behaviour or it does not (it is just a merely reliable indicator that does not completely rule out the possibility that Jones fails to do A). If the first, the dilemma defender claims that Frankfurt's attack on PAP is dialectically inappropriate against incompatibilists: once we make explicit the assumption of a deterministic causal connection between the prior sign and Jones' doing A, an incompatibilist would probably say that she no longer shares the intuition that Jones is morally responsible for what he does. Her view is, after all, that moral responsibility is incompatible with that kind of causal determination. But if the intuition that Jones is morally responsible is rejected, we have no counterexample to PAP. Thus, if Frankfurt's argument against PAP is to have any force for an incompatibilist, FSCs should be understood as not involving a deterministic connection between the prior sign and Jones' action. We are then on the second horn of the dilemma. But, now, if there is no deterministic causal connection of that sort, it is possible that Jones gives the sign (as a result of which Black fails to intervene) and nevertheless fails to do A. Thus, it is not true that Jones could not fail to do A. And, thus, we do not have a counterexample to PAP either.

The assessment of this argument is a complex issue. I will just mention here three lines of reply. First, the proponent of the FSC could hold onto the first disjunct (the prior sign causally determines that Jones does A) and downplay the incompatibilist's resistance to seeing Jones as morally responsible for what he does. At the very least, she could say that FSCs are successful counterexamples to PAP under the assumption of compatiblism. This would already be a significant result, given that, before Frankfurt's discussion, PAP was assumed by compatibilists and incompatibilists alike. Second, a proponent of the FSC could instead assume the second disjunct (the prior sign does not causally determine that Jones does A) and argue along the lines of Fischer's considerations against the ficker strategy: even if it is a possibility that Jones gives the prior sign and fails to do A, it is not clear that this possibility is robust enough (cf. Fischer 2007: 60). In fact, given that the prior sign is a reliable indicator, the possibility in question should be very extraordinary (i.e. very unlikely to be actualised). Arguably, such extraordinary alternative possibilities cannot account for our judgments of moral responsibility and 
are therefore not robust. A third line of reply consists of developing FSCs in which - as in Frankfurt's original case - there is no prior sign, therefore blocking the dilemma defence at its very start. This sort of FSCs is described by Mele and Robb (1998), and subsequently discussed by Fischer (1999), Kane (2003), Widerker (2003), and by Ferenc Huoranszki, in his contribution to this volume.

\subsection{The 'new-dispositional' defence}

Finally, a third argument for the conclusion that Jones could have done otherwise comes from the view that has been called 'new dispositionalism', versions of which are held by Smith (2003), Vihvelin (2004) and Fara (2008). New dispositionalists agree with some early compatibilists like Moore and Ayer that having the ability to do otherwise amounts to having a disposition, or a collection of dispositions. However, those early compatibilists relied on a simple conditional analysis of dispositions (roughly, on this analysis an object $\mathrm{x}$ has a disposition $\mathrm{P}$ just in case certain manifestation $\mathrm{Q}$ would obtain if $\mathrm{x}$ were in some appropriate conditions). New dispositionalists, on the other hand, rely on an approach to dispositions that became popular since Lewis' discussion of finkish dispositions (Lewis, 1997). On this 'new' account, having a disposition is having an intrinsic property that, in appropriate circumstances, would contribute to cause a particular outcome. According to this analysis, an object may have a disposition even if the disposition's manifestation fails to be triggered in the sort of conditions where it would normally be triggered. A very fragile glass vase, for instance, would normally break if it falls on the floor, but if may fail to break if it is very carefully packaged. The packaging does not deprive the vase of its fragility, but only prevents its manifestation from occurring. This is so because, as follows from Lewis' analysis, the fragility of the vase has to do with its intrinsic properties, which remain unaffected by the packaging.

Let us now consider a situation that is just like the original FSC, except for the fact that Black is not present (i.e., an ordinary situation in which Jones does A for his own reasons). About that situation, we are inclined to say that Jones has the ability to do other than A. After all, the whole point of Black's presence is to elicit the intuition that Jones could not have done otherwise. If Black is removed from the 
scenario, we no longer have that intuition and are rather inclined to say that Jones can do other than A. Now, if Jones has the ability to do otherwise in this case, and if having the ability to do otherwise is having a certain intrinsic property, then Jones must retain that ability when Black is back in the picture. The presence of Black does not deprive him of his ability any more than the packaging deprives the vase of his fragility. It prevents Jones from exercising his ability, but the ability is still in place. But if Jones is able to do otherwise, as it follows from this analysis, FSCs are no counterexample to PAP.

The assessment of this objection is a complex and on-going issue. ${ }^{3}$ A central issue is whether the ability to do otherwise that, according to new dispositionalists, Jones retains even in the presence of Black, is the relevant one for the debate between compatibilists and incompatibilists. More specifically, as suggested by Clarke (2009) and Whittle (2010), it may be argued that whereas Jones retains a general ability to do otherwise (and that this could be understood as the possession of a disposition analysed in terms of intrinsic properties), he lacks the sort of specific ability (i.e. the 'power to exercise a general ability in a given occasion') that incompatibilists like van Inwagen (1983: 12-13) took to be ruled out by the truth of determinism. And since, arguably, we should also understand PAP as involving this more specific ability, a FSC could still constitute a counterexample to it.

\section{Alternative possibilities vs actual sequences as the grounds of freedom}

Even if, for one reason or other, FSCs are not successful in showing that PAP is false, they may nevertheless be sufficient for motivating views on free will and moral responsibility in which alternative possibilities play no explanatory role. We can illustrate this by focusing on the debate about the grounds of free will and moral responsibility, as framed by Carolina Sartorio, both elsewhere (Sartorio 2016)

\footnotetext{
${ }^{3}$ Critical discussions of new dispositionalism are offered by Clarke (2009), Whittle (2010), and Vetter and Jaster (2017). In the present volume, the papers by T. Cyr, M. Hart, and N. Elzein and T. Pernu all discuss the notion of ability in a way that is relevant to the final evaluation of the view.
} 
and in her contribution to this volume. Rather than asking whether alternative possibilities are a necessary condition to free will, Sartorio focuses on the question of what grounds free will. The different views that aim to answer this question are not supposed to offer merely necessary (or merely necessary and sufficient) conditions of free will, but rather conditions in virtue of which an action is free. Sartorio characterises two broad answers to the question of what grounds free will: the alternative possibilities (AP) answer, and the actual-sequences (AS) answer. The main difference between the two is the role played by alternative possibilities. According to the AP answer, part of what makes it the case that an action is free is the fact that the agent had alternative courses of action open to her; courses of action that she did not take. Other things may be required in the explanation of freedom, including facts about the actual sequence of events leading to the action. But having alternative possibilities is a necessary condition that makes the explanatory work: part of the reason why someone is free is that she has alternative possibilities; a reason why someone may fail to be free is the mere absence of alternative possibilities. According to the AS answer, on the contrary, the presence or absence of alternative possibilities is irrelevant to explaining why an action is or fails to be free. Whether an action is free or not, according to the AS answer, is exclusively a matter of the actual events that result.

It is worth emphasising two features of the debate so construed: first, AP views do not claim that alternative possibilities are the complete grounds of freedom: everything freedom is grounded in. In fact, an AP view may take on board most or even all the positive claims made by an AS view. The disagreement is only about the AS theorist's negative claim that alternative possibilities are not part of what freedom is grounded in. Second, this negative claim that characterises AS views should be distinguished from the claim that alternative possibilities are not a necessary condition of free will. Drawing on the idea that necessary conditions are not always grounding conditions (Fine: 1994), AS theorists may accept that alternative possibilities are a necessary condition of free will and so that PAP is true. That is why whether FSCs are successful or not as counterexamples to PAP is not the main concern for AS theorists.

That does not mean, however, that FSCs are without interest for 
AS theorists. On the contrary, AS views are motivated by reflection on them. Whether or not Frankfurt succeeds in refuting PAP, his argument supports the idea that the reasons why an agent is free and responsible may lie wholly within the limits of the events that actually lead to the action: all we need to look at in order to explain why Jones is free and morally responsible is the actual sequence of events that results in his action. It is because this sequence of events satisfies certain metaphysical conditions (in addition to the relevant epistemic conditions) that we hold Jones responsible for what he did. It is only for that reason that we do so. We do not, in addition, have to even consider whether or not Jones could have done otherwise.

What exactly are the metaphysical conditions that Jones' action satisfies and that, in the AS views, make it the case that his action is free? This is a point where the various AS views differ from each other. On the very influential theory of Fischer and Ravizza (1998), Jones' freedom is grounded in the reasons-responsiveness of the mechanism that results in his action. That mechanism (ordinary practical deliberation) is reasons-responsive because it issues different outcomes depending on what reasons are presented to the agent (by contrast, the mechanism that involves direct manipulation by Black is not reasons-responsive in this sense). Sartorio (2016) offers an explicitly 'causalist' AS view, according to which all that matters for whether an action is free is the actual causal history of that action. In her view, Jones' freedom is grounded in his reasons-responsiveness, but his reasons-responsiveness is determined by the actual causal history of his action. What makes Jones reasons-responsive with respect to his action is that the action's actual causal history has, as a component, the absence of reasons for doing otherwise.

As can be seen in Sartorio 2016 and in Carlos Moya's contribution to this issue, part of the debate between AS views and AP views turns on whether AS views can accommodate apparent counterexamples to the claim that freedom supervenes on actual sequences understood as causal histories: i.e. the claim that, necessarily, any two actions that are indiscernible with respect to the causal histories issuing in them, are also equally free or unfree. This claim follows from the stronger claim that freedom is grounded in causal histories and, arguably, also from the basic AS commitment that freedom is grounded in actual sequences (Sartorio 2016: 34). That is why AS views face the 
challenge of explaining away the apparent counterexamples. Some of these counterexamples were originally presented by Peter van Inwagen (1983) as part of his defence of PAP from Frankfurt's attack. For our present purposes, we can focus on the following pair of cases described by Sartorio (2016: 56):

(Phones) I witness a man being robbed and beaten. I consider calling the police. I could easily pick up the phone and call them. But I decide against it, out of a combination of fear and laziness.

(No Phones) Everything is the same as in Phones except that, unbeknownst to me, I couldn't have called the police (the phone lines were down at the time).

The intuition here is that there is a difference in moral responsibility (and on the freedom condition attached to it) without a difference in the actual sequence that leads to inaction: it seems that I am morally responsible for the police not being alerted in Phones, but not in No Phones. And yet, the actual causal history that leads to the police not being alerted seems to be the same in both cases: a combination of fear and laziness. Whether or not the phone lines were in order seems to be irrelevant to the actual causal history. Thus, the pair of cases seems to be a counterexample to the supervenience claim that arguably follows from AS views. It also points to the relevance of alternative possibilities as a ground of freedom and moral responsibility, given that the only difference between Phones and No Phones seems to be in my ability to do otherwise than I actually do.

If the AS theorist is to honour the intuition that there is a difference in moral responsibility between Phones and No Phones, it seems that the only two options open to her are either (i) argue that, contrary to initial appearance, the causal history leading to inaction is not the same in both cases; or (ii) give up the supervenience claim, somehow arguing that it is not really a consequence of the basic claim that freedom is grounded in actual sequences. Sartorio (2016: 61) argues against this second strategy, and develops a subtle version of the first. Her account relies on the idea that causation is extrinsic in the sense that 'a causal relation between $\mathrm{C}$ and $\mathrm{E}$ may obtain, in part, owing to factors that are extrinsic to the causal process linking $\mathrm{C}$ and E' (Sartorio 2016: 71). In Phones and No Phones, the state of the phone 
lines is an extrinsic factor that contributes to determine different causal histories for my failure to call the police: given that in Phones the lines are in working order, my laziness and fear do cause my not calling the police. In No Phones, in contrast, because of the different extrinsic factors, my laziness and fear do not cause my not calling the police; at most, they cause my not trying to call the police. Sartorio thus concludes that Phones and No Phones, and similar pairs of cases, do not constitute a counterexample to the supervenience claim that arguably follows from AS views.

We have claimed above that the failure of FSCs as counterexamples to PAP do not prevent FSCs from being a source of inspiration for AS views. In the same spirit, it could be argued that the failure of Phones and No Phones as a counterexample to the supervenience claim does not prevent them from being a source of inspiration for AP views. Even if the two cases do differ in the causal histories leading to inaction, they certainly also differ in the availability of alternative possibilities, and it is natural for the AP theorist to take this difference as making the relevant explanation work. In fact, this seems to be van Inwagen's own purpose in presenting his cases. In the same direction, Carlos Moya, in his contribution to this volume, uses Phones and No Phones (and variations on them) to argue for an AP view. He asks us to consider a case that is just like No Phones, except for the fact that 'had I seriously considered calling the police, presumably for moral considerations, I would have found myself unable to make the decision to call because of an outbreak of intense anxiety and irresistible fear'. About this case, Moya claims that I am morally responsible for my decision of not calling the police (which, as in the original case, issues from a combination of fear and laziness), even if I could not have made a different decision. But, even in this case, Moya argues, there is something I could have done and did not do: I could have tried to make a different decision. And although this trying would not have been successful, its possibility is part of what explains that my decision is free. Thus, that I could have tried to call the police is an alternative possibility that contributes to grounding the freedom of my decision. Moya argues that the grounding character of this alternative possibility (or its robustness, as we could as well say) is supported by ordinary intuitions about attributions of moral responsibility: on the one hand, we tend to blame someone for 
what they did when they fail to do their 'reasonable best in order to behave in a morally right way'. This is what happens with the agent in the case considered: it seems that he is held blameworthy because he could have done better than he did (even if he could not have decided otherwise). On the other hand, it seems that he would not be held responsible for his decision if, for deep psychological reasons, he could not even try to choose otherwise. In that case, his status as a free and morally responsible agent would be compromised. Thus, Moya concludes, alternative possibilities may do grounding work and AP views are not refuted by cases like the one he considers.

\section{The papers in this issue}

We have focused on two central issues about alternative possibilities and the ability to do otherwise: whether FSCs are successful as counterexamples to PAP, and whether alternative possibilities are part of what grounds free will. Some of the papers in the present volume address these two issues directly. In 'Actual Causes and Free Will', Carolina Sartorio defends her own AS view, partially described above, focusing on the role that absences of reasons play on it. On the other hand, in 'Free Willl and Open Alternatives' Carlos Moya argues for an AP view, as explained above. Moya argues that the possibility of doing better from a moral point of view is a robust alternative possibility that grounds freedom in FSCs and the like. Other papers in the issue can also be put in the context of the debate between AS and PA theories: Taylor Cyr in 'Is Semi-compatibilism Unstable?' defends an AS theory like Fischer and Ravizza's from recent arguments based on what abilities allegedly are. In 'Supervenient Freedom and the Free Will Debate', Nadine Elzein and Tuomas Pernu offer a taxonomy of the free will debate centred in the requirement of alternative possibilities, and argue against a recently proposed AP view that they call 'supervenient libertarianism'. The other three papers presented here are more directly connected to the question of the success of FSCs as counterexamples to PAP. In 'Alternative Possibilities and Causal Overdetermination', Ferenc Huoranszki offers a comprehensive discussion of this issue and concludes that FSCs can only do their intended job under very substantive assumptions about the nature of agency, assumptions that Frankfurt's dialectical op- 
ponents need not share. Benjamin Matheson is also pessimistic about the success of FSCs and so in his 'Alternative Possibilities, Volitional Necessities, and Character Setting' he explores an alternative route to showing the irrelevance of alternative possibilities: the 'Volitional Necessities Argument', suggested by Daniel Dennett, which Matheson defends from libertarian replies. Finally, in 'A Modest Classical Compatibilism', Matthew Hart draws on Kratzer's semantics for modal expressions in order to articulate a defence of PAP from Frankfurt's argument against it. ${ }^{4}$

Pablo Rychter

Departament de Filosofia Facultat de Filosofia i CC.de l'Educació Universitat de València Avda. Blasco Ibáñez, 30 46010 València, Spain pablo.rychter@uv.es

\section{References}

Clarke, Randolph. 2009. Dispositions, abilities to act, and free will: the new dispositionalism. Mind 118: 323-351.

Fara, M. 2008. Masked abilities and compatibilism. Mind 117: 843-865.

Fine, Kit. 1994. Essence and modality. Philosophical Perspectives 8: 1-16.

Fischer, John Martin and Ravizza, Mark. 1998. Responsibility and Control: A Theory of Moral Responsibility. Cambridge University Press.

Fischer, John Martin. 1994. The Metaphysics of Free Will: An Essay on Control. Blackwell.

Fischer, John Martin. 1999. Recent work on moral responsibility. Ethics 110: 93-139.

Fischer, John Martin. 2007. Compatibilism. In Four Views on Free Will. Blackwell.

Frankfurt, Harry G. 1969. Alternate possibilities and moral responsibility. Journal of Philosophy 66: 829.

Ginet, Carl. 1996. In defense of the principle of alternative possibilities: Why I don't find Frankfurt's argument convincing. Philosophical Perspectives 10: 403-17.

Kane, Robert. 1996. The Significance of Free Will. Oxford University Press USA. Kane, Robert. 2003. Responsibility, indeterminism and Frankfurt-style cases:

${ }^{4}$ I want to thank Josep Corbí for his comments on a previous version of this article. Research leading to this work was partially funded by the research projects FFI2016-75323-P and FFI2015-66372-P. 
a reply to Mele and Robb. In Moral Responsibility and Alternative Possibilities: Essays on the Importance of Alternative Possibilities, ed. by David Widerker and Michael McKenna, Ashgate.

Lewis, David. 1997. Finkish dispositions. Philosophical Quarterly 47:143-158. Mele, Alfred R. and Robb, David. 1998. Rescuing Frankfurt-style cases. Philosophical Review 107: 97-112.

Sartorio, Carolina. 2016. Causation and Free Will. Oxford University Press UK.

Smith, Michael. 2003. Rational capacities, or: How to distinguish recklessness, weakness, and compulsion. In Weakness of Will and Practical Irrationality, ed. by Sarah Stroud and Christine Tappolet , 17-38. Oxford: Clarendon Press. Van Inwagen, Peter. 1983. An Essay on Free Will. Oxford: Clarendon Press.

Vetter, Barbara and Jaster, Romy. 2017. Dispositional accounts of abilities. Philosophy Compass 12.

Vihvelin, Kadri. 2004. Free will demystified: a dispositional account. Philosophical Topics 32: 427-450.

Whittle, Ann. 2010. Dispositional abilities. Philosophers' Imprint 10 (12).

Widerker, David.1995. Libertarianism and Frankfurt's attack on the principle of alternative possibilities. Philosophical Review 104: 247-61.

Widerker, David. 2003. Blameworthiness and Frankfurt's argument against the principle of alternative possibilities. In Moral Responsibility and Alternative Possibilities: Essays on the Importance of Alternative Possibilities, ed. by David Widerker and Michael McKenna, Ashgate. 